\title{
MALNUTRITION IN CHILDREN UNDER THREE YEARS OF AGE IN ASHANTI, WEST AFRICA
}

\author{
BY \\ BEATRICE A. S. RUSSELL, M.D. Edin., F.R.C.P.E., D.T.M. \& H. \\ Medical Officer, Colonial Service, Gold Coast
}

At a time when problems of food supply are prominent in all parts of the world, a clinical account of malnutrition in young children in Ashanti may be of more than local interest.

Ashanti lies in West Africa, north of the Gold Coast. Kumasi, the capital, is situated in the tropical forest belt, with roads radiating from it in all directions. A Welfare Centre was opened in the town fifteen years ago to provide medical care for children and for pregnant women. At this centre there were last year over 50,000 attendances, and cases of under-nutrition and malnutrition were frequently seen. Although the two conditions tend to merge, it is with the latter that this article deals.

Background. The people live in small villages of mud-walled houses in forest clearings, and even the town dwellers constantly go and come from ' bush.' Food is supplied by the small subsistence farms, which are cultivated with the hand hoe after the undergrowth has been cut and burned. Soil fertility is maintained by shifting cultivation only, and the chief crops are maize, plantains, and rootsthe roots being mainly cassava and cocasia antiquoran. Maize is eaten fresh-roasted at harvest, but is more often stored to make porridge, after it has been ground and partly fermented. Plantains and roots form the basis of most meals, of which there are two a day, and are eaten after boiling, or more often after boiling are beaten to a dough-like substance or 'fu-fu', and eaten with a pepper sauce containing vegetables.

Of domestic animals none larger than sheep and goats survive, on account of the prevalence of tsetse fly. These animals are a form of wealth; they are eaten only on special occasions, and they are not milked. Fowls are used in much the same way. Eggs, being potential chickens, are rarely eaten. Meat is supplied irregularly by hunters; fish is imported smoked and sun-dried, but it is too expensive to be used by most of the people except as a flavouring.

Thus, to summarize the food position, no milk is used for children except the mother's; protein is in short supply, especially for the children, who are served after their elders; and carbohydrate, of poor quality according to Clarke (1932), forms the bulk of each meal.

Malaria is endemic, and mainly of the subtertian variety. Worm infestation is common, particularly ascariasis.

In those surroundings, however, the baby, once he has survived the hazards of birth, starts life fairly well. Breast feeding is universal, and is continued for eighteen months, two years, or longer, unless the mother becomes pregnant again. Most women have ample milk for six months at least, and as the child grows he begins to eat bits of starchy food thrust into his hand. He may or may not be given maize porridge, but whenever he cries he is always offered something to eat.

When the infant becomes a toddler he fares well or ill according to the amount of care given by the mother and according to the severity of the malaria from which almost all children suffer. At this stage there is marked lack of protein in the child's food, and probably only continued breast feeding tides him over a critical period. When he begins to move about by himself ascaris infection takes place, and enteritis from various causes is common, so that his condition tends to be below par. Nevertheless, to the untrained eye the toddler between one and three years does not look undernourished, and indeed may appear plump. Frequently, however, this appearance of well-being is deceptive, because although subcutaneous fat is present, there is often also slight general oedema. This generally passes unnoticed, and spontaneous cure is the rule as the child becomes older and better able to fend for himself. In cases of definite malnutrition oedema is more marked, and swelling of the hands and feet may be the first sign to attract the mother's attention.

History. The history in a developed case of malnutrition is unsatisfactorily vague as to prodromata, but certain points are generally found common to all. The child had been healthy at birth and had done well for eighteen months or two years, i.e. up to the birth of the next child. Illness of the displaced baby is so common that there is a general belief among the people that the unborn child exerts a direct and malign influence upon his brother, and the latter is often, therefore, sent to stay with relatives. When finally the mother comes to the clinic for advice, she appears with a plump baby on her back and the ex-baby hardly able to walk. Any history of precipitating illness other than that of 'fever' (malaria) is indefinite, 
and the variety of symptoms complained of is as interesting as it may be misleading, ranging from diarrhoea to swelling of the hands and feet or face, worms, cough, loss of appetite, rumbling in the stomach, and in more advanced cases, inability to walk. For whichever symptom the mother is concerned about, she wishes to be supplied with a bottle of medicine.

Condition on examination. The patient is a toddler and under three years of age. The appearance is characteristic, and with some practice even early cases can be recognized. The child does not look thin, partly because subcutaneous fat is present and partly because of general oedema. The latter may be so slight as hardly to pit on pressure, but it gives to the child's cheeks a typically heavy and

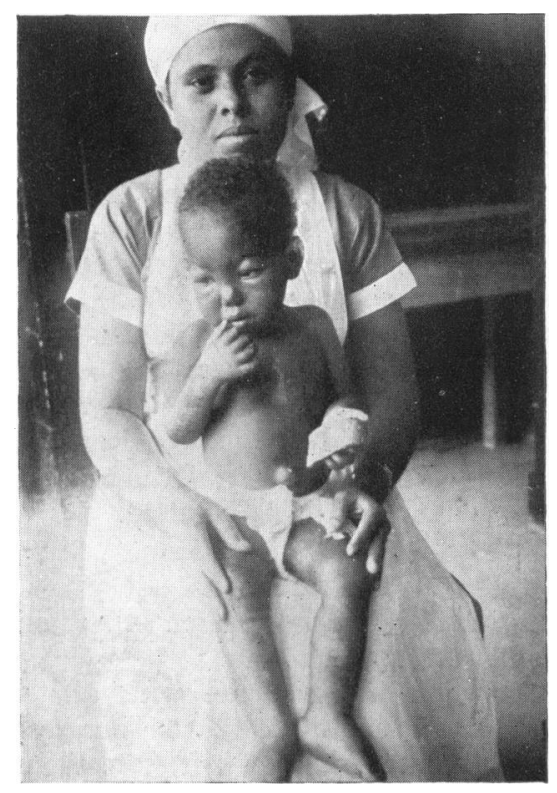

FIG. 1.-Case of malnutrition, taken one week before death.

slightly pendulous appearance. Pitting can as a rule be made out over the shins and on the backs of the hands and feet. In spite of the stolid appearance, the child is irritable and cries readily when examined. He sits down or supports himself as if his legs were weak, and in fact, muscular tone is very poor. Ankle and knee jerks are absent. The hair is sparse, brown and dry, and the skin is dry, with crazy-pavement markings most distinct where oedema is most marked. Small ulcers are often present on the legs and buttocks. In the mouth, ulcers, thrush, and redness and soreness of the tongue are common. The abdomen is blown out, and the mother states that the child has diarrhoea. Blood and mucus are generally found in the stools, also ascaria ova and flagellates. The pulse is rapid, but cardiac enlargement has not been demonstrated. Cough, probably due to oedema, is generally present. There may be an enlarged spleen, and malaria parasites may or may not be found in the peripheral blood. Anaemia is always considerable, with haemoglobin (Talquist) of 5 per cent. or less. The red cell picture is that of dimorphic anaemia as described by Trowell (1942) in East Africa. The temperature is not raised unless active malaria or other infection is present. The urine not infrequently contains albumen, and casts are sometimes found.

Prognosis. The prognosis depends upon how soon correct treatment is instituted. In all except early cases, unless treatment in hospital is agreed to, the child goes steadily downhill, and dies often as a result of some terminal infection. Of recent years the outlook in hospital has become more cheerful, now that the all-important place of diet in causation and treatment has been recognized. But no means has as yet been found of assessing which case will respond to treatment and which will not do so. Excessive and persisting oedema with albumen are bad prognostic signs, while early and steady reduction of swelling with early disappearance of albumen are hopeful. In all cases, however, relapse is common.

Differential diagnosis. Once the child has been surveyed as a whole there is no particular difficulty in diagnosis. The absence of definite localizing signs, the scanty hair, oedema and unhealthy skin are all helpful pointers. The medical officer must beware of being side-tracked by individual signs and symptoms, and of overlooking the fundamental malnutrition. Only drastic revision of the child's diet will save the child's life, if it can be saved.

Treatment. Little is gained by the treatment of symptoms unless and until the need for a suitable diet has been recognized and dealt with. Because of the unhealthy state of the digestive tract, food must be bland and easily digested. At the same time it is important that local food-stuffs should be utilized as far as possible, so that relapse may be avoided when the child is discharged from hospital and has to return to ordinary family foods. From one's knowledge of how deficient these foods are in protein, the aim has been at once to supply an easily obtained and easily digested form of protein. To this end the local gruel made of fine-ground and fermented maize, with milk and eggs added, forms food which is easily taken. Soups made from bone stock and with finely mashed liver are also given from the first. Vegetables and coarser carbohydrates are added as improvement takes place. The only foreign constituent used is tinned milk.

Vitamins. The results from giving individual vitamins either by mouth or by injection have been found by the writer disappointing on the whole, a conclusion which is in line with other work along the same lines (Richards, 1945). Vitamins B1 and $\mathrm{C}$ have sometimes been observed to have produced a temporary diuretic action which has not, however, led to permanent improvement. Nicotinic acid does not appear to have any specific action. Riboflavin may perhaps have some effect in helping to clear up sore mouth. Crude liver extract, such as Campolon, has been found useful in cases which 
have been in hospital for a time and are at a standstill. Cod-liver oil has not been available during the war, and the local palm oil, though rich in carotene, has an undesirable laxative action. One of the most distressing features of the condition is diarrhoea, and for this symptom drug control has not been found effective. It clears up as general improvement takes place.

Plasma. Among the cases treated by the writer it was possible to treat only one child with intramedullary plasma. The dose given was a small one, and no permanent good results were observed. This, however, may be a form of therapy worth further trial.

Next in value to careful feeding, the most important single factor in bringing about recovery is good nursing. These children should be guarded against chill, and the unhealthy skin must be cared for. Oiling with the local palm-kernel oil appears to be useful for this purpose.

If oedema persists for a week or so, more drastic measures sometimes meet wih gratifying results. The diuretic, 'Neptal', has been used, in doses of 0.3 c.c. subcutaneously, and after one dose the child's whole appearance may change overnight, with disappearance of most of the oedema. If the tissues fill up again, a second dose may result in permanent relief. In unfavourable cases the diuretic appears to produce no effect.

As soon as the oedema begins to disappear mental improvement is striking, and for the first time the child begins to sit up by himself and to take some interest in his surroundings. Appetite improves gradually, but it is some time before the diarrhoea subsides. The blood and mucus in the stools generally disappear shortly after admission, and are undoubtedly largely due to the irritant enemata to which the child has been subjected before admission. Genuine gain in weight does not occur until the patient has been in hospital for some time, and progress is often checked, with temporary increase of oedema. When the oedema has finally been relieved the extreme flabbiness of the child can be appreciated; arms and legs are thin, and of a soft, dough-like consistence, with a marked lack of muscular power.

As general improvement progresses the unhealthy superficial layers of the skin darken and flake off, the hair begins to grow and darken, and the condition of the mouth clears up. In unfavourable cases the oedema increases, the child becomes more drowsy, is more difficult to feed, and slowly fades out, unless carried off by some terminal infection.

\section{Comment}

How far malnutrition and under-nutrition may be considzred as separate entities is rather difficult to say, arid undoubtedly the one tends to merge into the other. The malnourished child, with his failing health and strength, eats less and less, and gets even less than his normal share of the important foods, which in any case are in short supply, so that a vicious circle is set up. The child may finally be eating nothing but a little starch.

Clinically, the condition seems to be identical with the 'Kwashiokor Disease' in the Gold Coast Colony, described by Williams (1933), but the writer has not found it to be associated with a maize diet, and in the few cases examined postmortem, liver damage was not so extensive as Williams found it in that disease. In uncomplicated cases death in hospital seldom occurs, but in two cases recently examined, the livers, though extensively vacuolated, were by no means diffluent.

The clinical picture is interesting when compared with reports from other parts of the world, for example, with the report on nutrition in Newfoundland (Med. Survey, 1945) where the basic rations are very different.

Improvement, and reduction of incidence, can only be expected as knowledge of causation spreads and as the standard of living is raised.

\section{Summary}

Malnutrition as seen in children in Ashanti after weaning is described.

The condition is associated with low protein diet, and is distinguished by the occurrence of oedema, unhealthy skin and hair, sore mouth and diarrhoea.

The line of treatment is indicated.

This paper is published by permission of the D.M.S., Gold Coast.

\section{REFERENCES}

Ciarke, A. (1932). Trans. Roy. Soc. Trop. Med. Hyg., 26, 3.

Trowell, H. C. E. (1942). Afr. med. J., 19, 268.

Richards, M. B. (1945). Brit. med. J., 1, 433.

Williams, C. D. (1933). Arch. Dis. Childh., 8, 48.

Med. Survey Nutr. Newfoundland (1945), Can. Med. Ass. J., 52, 227. 